\title{
EL ESCRITOR MARROQUÍ MUHAMMAD ZAFZĀF. ACERCAMIENTO A SU PRODUCCIÓN NARRATIVA. EL RELATO
}

Fernando Ramos López

\begin{abstract}
The aim of this article is to make an approach to Muhammad Zafzāf's short-stories. M. Zafzāf (1945) belongs to the "new generation" of Moroccan narrators that began to publish works of recognised literary matureness around 1970. They received numerous and diverse influences, both from Arab literature as well as from Western literature. An important source of creativity was the recuperation of the local traditional element. The space in which Zafzāf's short-stories take place are microcosms susceptible to symbolic interpretation where the characters live at the mercy of the circumstances that befall them. Time presents two facets: of reality and of utopia. In Zafzāf's narrative symbolism, impressionism and existencialism are combined, being movements in which the writer finds the means to express anguish, tabus and utopia with a language and audacity which is rare in modern Moroccan narrative.
\end{abstract}

\section{Muhammad Zafzāf y la "nueva generación" de narradores marroquíes.}

Es opinión comúnmente aceptada que el relato de expresión árabe surge en Marruecos hacia los años cuarenta ${ }^{1}$. En este surgimiento intervienen la influencia de la narrativa árabe oriental, especialmente la egipcia, y el entrenamiento que supuso el ensayo literario gracias al desarrollo de la prensa marroquí, además de las aportaciones de la narrativa occidental, especialmente la francesa. A partir de esta década el nuevo género literario evoluciona a lo largo de la segunda mitad del siglo XX. Desde la gestación de la conciencia nacional de los intelectuales vinculados a la lucha anticolonialista, cuya creatividad artística en el campo de la narrativa se presenta muy limitada, hasta el desarrollo de la conciencia literaria de los

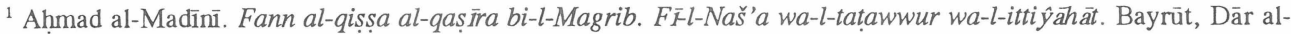

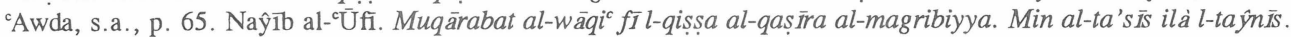
Al-Dār al-Baydā', al-Markaz al-Taqāîi l-'Arabī, 1987, p. 19. Abderrahmán Cherif-Chergui. "Introducción", en Literatura y Pensamiento marroquies contemporáneos. Madrid, I.H.A.C., Rabat, Facultad de Letras, 1981, p. XX. Pedro Martínez Montávez. Introducción a la literatura árabe moderna. Madrid, CantArabia, 1985², p. 182. Si bien

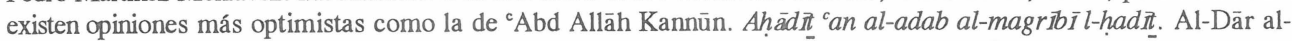

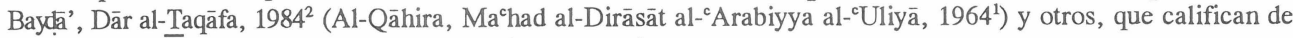
narrativa breve producciones de los años treinta y anteriores.
} 
narradores actuales, la evolución de la narrativa breve marrroquí escrita en lengua árabe viene marcada por la ampliación del horizonte intelectual de los escritores, así como por el progresivo ejercicio y perfeccionamiento del uso de las técnicas narrativas ya empleadas entre los narradores orientales, la apertura del abanico temático y la recuperación del legado nacional.

Muhammad Zafzāf (n. 1945) ${ }^{2}$, narrador de vocación mantenida desde los años sesenta, se sitúa en la denominada al-ŷyl al-ŷadìd, nueva generación de narradores marroquíes. Los primeros ejemplos de su producción narrativa se localizan entre el realismo social y el realismo crítico de finales de los sesenta. En ellos el autor intenta destapar la realidad a través de una situación concreta resultado, no de una incursión moral forzada, sino de una extracción natural desde el fondo del personaje y el conjunto de circunstancias que conforman el argumento del relato. Se trata de una realidad de pérdida tanto individual como social en la que los personajes están encerrados en un círculo vicioso y sometidos, en propias palabras, a una "opresión abstracta" insostenible. Pero el inicio definitivo de la trayectoria narrativa de Muhammad Zafzāf se produce a partir de los años setenta, formando parte activa del notable incremento de publicaciones literarias que se produce en Marruecos en esos momentos gracias a la aparición de nuevas revistas y suplementos culturales de carácter progresista.

Es precisamente el término "ŷadīl" ("nuevo") el que se repite incesantemente en los escritos teóricos de los narradores y los críticos del momento. ${ }^{3}$ No obstante, el término no es empleado con el mismo significado por todos los autores, ni todas las producciones calificadas de "nuevas" reciben este calificativo por tener en común un conjunto homogéneo de elementos característicos de un estilo concreto e innovador, sino que son "nuevas" en relación a las producciones anteriores. Asimismo, no todos los autores incluidos en este grupo (Muhammad Barrāda, Idrīs al-Jūrī, Aḥmad Būzfūr o Muhammad Šukrī, entre otros) comparten la misma opinión frente a conceptos fundamentales como "realismo", ${ }^{4}$ ni tampoco todos ellos confieren igual importancia a la idea de la "especificidad marroquí" de sus relatos respecto del resto de la narrativa árabe moderna. ${ }^{5}$ Estos autores, nacidos entre 1935 y 1945 , comienzan a publicar sus primeras obras de reconocido interés en torno a 1970 y sobre todo

\footnotetext{
${ }^{2}$ Natural de Sūq al-Arbicā'. Quedó huérfano a los cinco años. Estudió en Quenitra en la escuela francófona. Desde 1964 trabajó como periodista en Rabat en la Agencia Marroquí de Noticias y en el periódico Al- ${ }^{\mathrm{A}}$ Alam, labor que le ayudaría a "perder el miedo a la pluma" y que durante los años sesenta y setenta compagina con la literatura. Muhammad Zafzāf es miembro de la Unión de Escritores Marroquíes desde 1968 y sus publicaciones abarcan además de la novela y el relato, la traducción del francés y la crítica literaria. Actualmente es profesor de enseñanza media en Casablanca.

${ }^{3}$ Véanse por ejemplo los estudios aparecidos en $\bar{A} f a ̄ q, 3$ (especial relato), (1979?); M. Znỉbar. "Ayna yattaŷih aladab fi 1-Magrib al-Aqșà?" $A l-\bar{A} d a \bar{b}$ III (1978), pp. 4-11; I. Al-Nāqūrī. "Madjal ilà mafhūm al-taŷdîd fí 1-adab almagribī l-mucāșir" Al-Ādả, XI-XII (1981), pp. 167-177.

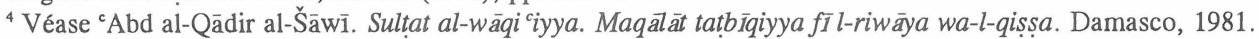

5 P. Šāwūl. 'Alāmāt min al-taqăăfa al-magribiyya al-hadîna. Beirut, 1979. Tres cuestiones éstas, "novedad", "realismo" y "especificidad", susceptibles de un detenido éstudio y que consideramos de gran importancia en la evolución de la narrativa marroquí moderna.
} 
coinciden en la necesidad de modernizar la narrativa marroquí e impulsarla hacia su madurez.

Los setenta son una década de "buen augurio" para el relato árabe en Marruecos. Es una época de despegue y de investigación creativa en el campo de la narrativa. Tras un período de imitación y seguimiento de las técnicas tradicionales comienza entre estos narradores la búsqueda de un estilo propio. En este sentido, mientras que la narrativa árabe experimenta en el Mašriq un momento de convulsión tras el gran desarrollo del realismo de los años cincuenta y sesenta, el relato en lengua árabe va a convertirse rápidamente en Marruecos en la forma literaria más moderna. Atrás quedan las ilusiones románticas para dar paso a una imagen actualizada de la realidad marroquí tendente hacia el futuro.

En este tiempo de investigación los narradores marroquíes eligen unos modelos y desechan otros; no se limitan a leer las producciones narrativas orientales, sino que amplían sus horizontes a la poesía, la crítica, la filosofía, la sociología y, por supuesto, la narrativa occidentales del siglo XX. En ellos, igual que en los escritores del Mašriq, concurren numerosos conceptos estéticos, estilos, escuelas, tendencias y objetivos, resultado de las distintas lecturas que han llevado a cabo en su afán de renovación y modernización. En el caso de los narradores marroquíes este aluvión de influjos tiene triple origen: Uno, la narrativa occidental, a través de lecturas a veces indiscriminadas que van desde Kafka hasta Hemingway, desde Camus hasta Joyce, o desde Proust hasta Virginia Woolf, de modo que se vuelve imposible precisar las influencias o el reflejo de las lecturas concretas de cada autor más allá del reconocimiento de características generales o elementos típicos fácilmente identificables. Dos, la narrativa árabe oriental, desde Maḥūz a Gadat al-Sammān, desde Yahyà Haqqī a Yūsuf Idrīs. ${ }^{6}$ Y finalmente, el propio patrimonio cultural, en absoluto reñido con la modernidad ni con la imaginación creadora, más bien al contrario, en el que los narradores marroquíes, como los árabes en general, encuentran elementos atemporales que son puestos al servicio de la narrativa moderna y son el mejor ejemplo práctico de recuperación del pasado. A todo ello debemos añadir la lectura y posterior traducción al árabe de importantes obras de teoría y crítica literarias occidentales de las que autores y críticos marroquíes se harán eco en sus obras (Georg Lukácks, Lucien Goldmann, Roland Barthes) ${ }^{7}$.

Progresivamente, los narradores marroquíes van intentando el tratamiento de una problemática particular que, aun siendo en lo fundamental común a la vivida anteriormente

\footnotetext{
${ }^{6}$ Remitimos a Fernando de Ágreda. Encuesta sobre la literatura marroqui actual. Madrid, Instituto Hispano-Árabe de Cultura, 1975. Cuadernos del «Seminario de Literatura y Pensamiento Árabes» $n^{\circ} 2$.

${ }^{7}$ Georg Lukácks (Ŷūrŷ Lūkātš). Dirāsàt fịl-wäqiciyya (Estudios sobre realismo). Damasco, 1972², y del mismo autor Dirāsăt fĩ l-wāqiciyya al-ürubiyya (Estudios sobre realismo europeo). Damasco, 1972, de gran difusión entre los críticos y los autores marroquíes. Especial interés muestran los narradores marroquíes por los enfoques estructuralistas de Lucien Goldmann (Lūsyān Gūldmān). Al-Manhaŷ̀iyya fī cilm al-î̀timāa al-adabī (Sociología de la novela). Beirut, 1981. (Trad. por Muștafà 1-Misnāwī), o Roland Barthes (Rūlān Bārt). Dara ŷat al-ṣifr li-l-kitảba (El grado cero de la escritura). Beirut, 1980. (Trad. por Muhammad Barrāda).
} 
en el Mašriq, se presenta en el Magrib con ciertos aspectos diferenciales y que está constituida por factores propiamente marroquíes, magrebíes, como el componente beréber, el predominio del islam en mayor grado que en el oriente árabe, la propia experiencia colonial, la acusada diglosia y la particular situación geopolítica, económica y social del país.

\section{La narrativa breve de Muhammad Zafzāf.}

En este contexto, la producción narrativa de Muhammad Zafzāf presenta un carácter universalista y a la vez particular, resultado de la interacción de los tres ejes fundamentales en torno a los cuales gira toda la producción literaria marroquí -y antes la árabe en generala partir de los primeros años setenta: la recepción de las literaturas occidentales, directa 0 indirecta, desordenada o selectiva; los progresos alcanzados por los autores de la generación anterior ('Abd al-Maŷīd b. Ýallūn, 'Abd al-Raḥmān al-Fāsī o Aḥmad 'Abd al-Salām alBaqqālī, entre otros), y el reencuentro con el propio patrimonio cultural, de una sorprendente actualidad. Muhammad Zafzāf reclama un mayor conocimiento por parte de la crítica oriental de las obras escritas en árabe que aparecen no sólo en Marruecos, sino también en Argelia y Túnez, y en otros países árabes de la periferia como los del Golfo, Sudán o Mauritania. En su opinión, los jóvenes narradores marroquíes conocen bien la literatura árabe oriental, e incluso están al corriente de nombres nuevos a los que la propia crítica aún no ha prestado atención. ${ }^{8}$

Zafzāf reconoce, y es uno de sus objetivos, la necesidad de buscar los mecanismos necesarios para conseguir expresar en lengua árabe todas las facetas de la realidad y crear una escritura aceptada, primero por los editores y los críticos, y luego por la mentalidad del lector. Para evitar caer en acusaciones gratuitas de "afrancesamiento", Zafzāf reclama del lector una visión global de las producciones de la generación nueva a partir de la cual es posible reconocer la lucha ejercida por los autores contra el imperialismo. Aunque en sus escritos se detecte una cierta contaminación sintáctica extranjerizante, ya sea por influencia de las lecturas del autor, por efecto del bilingüismo o por un extremado afán de renovación, el objetivo es siempre contribuir al desarrollo de una creación literaria árabe marroquí capaz de expresar las inquietudes de su pueblo. En su opinión, el legado no debe ser objeto de copia e imitación indiscriminada, sino que el escritor ha de tener una visión selectiva del mismo y adecuada a la propia realidad presente. ${ }^{9}$

El realismo es, más que una tendencia literaria, el marco estético en el que se aglutinan el conjunto de narradores marroquíes de la nueva generación. En él tienen cabida el romanticismo de ${ }^{\mathrm{C} A b d}$ al-Ŷabbār al-Sahịmīi, el simbolismo de Muhammad Ibrāhīm Bū- ${ }^{\mathrm{c}} \mathrm{All}$ ū, el existencialismo de Idrīs al-Jūrī, el utilitarismo de Janāta Bannūna o la ideología de Muhammad Barrāda o ${ }^{\mathrm{A}} \mathrm{Abd}$ al-Karim Gallāb, diferentes modos de expresión a través de los

\footnotetext{
${ }^{8}$ M. Zafzāf. "Al-Qișșa al-carabiyya: ayna al-wāqiic al-ŷadīd?" $A l-\bar{A} d \bar{a} b$, I (1971), 36.

${ }^{9}$ P. Šāwūl. Op. cit. , p. 63-67.
} 
cuales los narradores marroquíes manifiestan su percepción de una realidad nacional de atraso y secuelas del colonialismo, pobreza, sometimiento e ignorancia. La incesante búsqueda de causas y efectos en la realidad que los narradores marroquíes vuelcan en sus historias, unas veces, y la marcada visión ideológica inyectada en los relatos, otras, colocan a menudo en un segundo plano la marcha de los acontecimientos y las relaciones entre los personajes de sus narraciones. Ello conduce con frecuencia a la recreación de una realidad inexplicable y sobre todo decepcionante, repleta de dolor, tristeza y abatimiento, que domina tanto a los autores como a sus obras. En este contexto, los relatos de Zafzāf evidencian desde el principio una especie de liberación de ataduras que los sitúa en una perspectiva distanciada que es, en nuestra opinión, lo que confiere a sus relatos la autonomía de ficción literaria respecto del autor. Este distanciamiento demuestra la existencia en el escritor de una conciencia creadora ligada a la conciencia social pero independiente de ella. No es Muhammad Zafzāf el único narrador que ha conseguido dar este paso decisivo en la evolución de la narrativa árabe en Marruecos; ejemplo de ello consideramos a otros autores como ${ }^{~} \mathrm{Abd}$ al-Ŷabbār al-Sahịmīi ${ }^{10}$ o Muhammad Barrāda. ${ }^{11}$

En la trayectoria literaria de Muhammad Zafzāf, Aḥmad al-Madīnī distingue dos etapas: una que denomina de "realismo crítico" y otra de "realismo nuevo". ${ }^{12}$ En nuestra opinión, las dos etapas que observa al-Madīnī no son sino los primeros intentos a la manera que se venía haciendo en los sesenta y el verdadero inicio de la producción narrativa del autor, respectivamente. Paralelamente a la evolución experimentada por el escritor hacia la configuración de su propio estilo, los componentes de "realismo crítico" de los primeros trabajos se mantienen presentes a lo largo de sus publicaciones reflejando diferentes aspectos de la sociedad marroquí, sobre todo la urbana. En los primeros relatos el autor se esfuerza por captar una imagen de la realidad y profundizar en ella en tanto que idea y actitud. La imagen escogida suele revelar un mundo en proceso de degradación y bloqueado por la miseria material o espiritual. Los personajes representan destinos individualizados y colocados ante la vista del lector mientras buscan el modo de superar sus necesidades. A pesar de las limitaciones que conlleva esta opción, Zafzāf logra aportar en sus primeros relatos visiones agudas y personales que reflejan los asuntos fundamentales que convulsionan su conciencia social. Hâamid al-Nassāŷy ${ }^{13}$ es más severo en su análisis. Este crítico opina que en sus primeros relatos Zafzāf intenta un acercamiento a la realidad social condicionado por su perspectiva personal y selectiva. El autor se conforma con crear personajes y mundos inmóviles sin llegar a profundizar en los problemas de la gente, las cuestiones sociales, económicas o espirituales, componiendo relatos en los que se limita a hacer una observación simplista y superficial del curso de la vida marroquí.

${ }^{10}$ Lo demuestra su colección Al-Mumkin min al-mustahıl (1969), algunos de cuyos relatos podemos leer en español: Lo posible de lo imposible. Madrid, 1971. (Trad. F. de Ágreda y A. A. Jalaf).

${ }^{11}$ Buena muestra de ello es su novela Lucbat al-nisyān. Rabat, 1987. (El juego del olvido. Madrid, LibertariasProdhufi, 1995. Trad. B. Molina y M.I. Lázaro.)

${ }^{12}$ A. al-Madinī. Op. cit. p. 357 y ss.

${ }^{13}$ Al-Adab al-'arabī l-mu 'āṣir fī l-Magrib al-Aqșà. El Cairo, 1977. Citamos por 2² ed. 1985, pp. 444 y ss. 
La segunda etapa o inicio definitivo de la personal producción narrativa de Muhammad Zafzāf se pone de manifiesto desde la primera colección, Hị̂ār fị layl muta'ajjir (Diálogo al final de la noche) (1970), que incluye relatos como "Al-Dafn" ("El entierro"), en los que el autor incorpora nuevos componentes técnicos y temáticos que contribuyen firmemente a la renovación de la narrativa breve marroquí. Componentes que se mantienen y desarrollan en relatos como "Al-Yarāda" ("El saltamontes"), incluido en la segunda colección Buyūt wātía (Casas bajas) (1977), y en otras numerosas muestras repartidas por el resto de las colecciones. ${ }^{14}$ Este inicio definitivo de la trayectoria literaria del autor no sólo es el resultado de la depuración de la técnica sino también el fruto de un enriquecimiento intelectual y personal del autor. Un manejo más consciente de las técnicas narrativas del relato, la creación del narrador y sus puntos de vista, el entramado de las acciones, la animación de los personajes y sus procesos mentales, el diseño de las coordenadas espaciales y temporales o el control sobre la ideología, permiten a este autor crear un universo de ficciones con sello propio.

El mundo narrativo de Zafzāf está compuesto por dos mitades complementarias: una mitad viene dada por el acontecimiento concreto concebido en su dimensión social, y la otra mitad está constituida por la realidad concreta recreada en su dimensión individual. Esta dualidad acompaña siempre los contenidos de los relatos de Zafzāf. La primera mitad se manifesta en la observación del suceso y la descripción del mismo a través de impresiones instantáneas con las que el autor transmite de la realidad a la ficción narrativa ciertos aspectos de la vida de la gente, las preocupaciones y los encuentros y separaciones que se establecen entre ellos. La segunda mitad supone un paso más en la profundización del acontecimiento para indagar en el drama individual y descubrir la filosofía de la vida de un personaje y la visión que éste tiene del propio yo y su ensoñación del otro. El destino de los personajes y los contactos que se establecen entre ellos así como los conceptos del origen y la muerte como límites ciertos de la existencia, pero inaccesibles al conocimiento humano, son los cuatro elementos básicos que componen el campo de investigación de la narrativa de Muhammad Zafzāf.

En el mundo recreado por los relatos de Zafzāf domina la convicción de que la separación de los individuos es una cuestión inevitable. La relación entre el yo y los demás es un vínculo cortado y muchas veces la desconexión se produce también entre el individuo y su entorno directo, su lugar y su tiempo. De este modo, además de renovar personajes ya conocidos en la narrativa marroquí, Zafzāf aporta otros personajes nuevos al muestrario de modelos tan repetidos en las publicaciones de las décadas anteriores. Es el caso del individuo enfrentado a su propio destino, apartado de presiones temporales, espaciales o sociales que evidencien límites nacionales; personaje que, a menudo, interioriza la realidad observada por él de modo que el relato se convierte en un conjunto de sensaciones punzantes alejadas del

\footnotetext{
${ }^{14}$ La producción narrativa de Zafzāf consta hasta el momento de redactar este trabajo de nueve colecciones de relatos y ocho novelas cuyos títulos detallamos más abajo.
} 
concepto de pertenencia a una tierra o a una sociedad determinada, mostrándose, a veces, desvinculado del tiempo al perderse entre las revueltas de sus obsesiones, lo que inevitablemente le conduce al corte de la comunicación y la ruptura entre él y los demás. Esta situación límite aparece originada por la opresión que el individuo experimenta debida fundamentalmente a la injusticia social y a la represión existente en su entorno. Sin embargo, no rechaza activamente la situación ni se esfuerza por cambiarla, y si lo hace sabe que su intento está abocado al fracaso. En esa situación/actitud de ruina y frustración el personaje oprimido busca un paliativo en la utopía y sueña despierto. Las raíces, el padre y las tradiciones locales, frente a la visión del otro, el europeo, especialmente a través de la mujer como puente, son objeto de continua idealización.

Desde el inicio de su trayectoria literaria, Zafzāf formula su concepto de la literatura y la finalidad de la misma sobre una base de lecturas y reflexiones que el propio autor pone de manifiesto en diversos artículos y entrevistas. En la línea de narradores europeos como Henry James o Herman Broch, Zafzāf concibe la literatura como modo de conocimiento del ser humano y del mundo, y afirma que "el narrador comprende el mundo a través del intento de comprensión de sí mismo y del vínculo existente entre él y la dinámica de la naturaleza eterna" que debe ser mostrada en toda su desnudez, su grandeza y su miseria. ${ }^{15}$ De este modo, la concepción literaria de Muhammad Zafzāf se presenta como un eco de la metamorfosis experimentada por la narrativa europea moderna en relación con los clásicos del XIX (Maupassant; Tolstoi y Dostoievski) cuando a principios del siglo XX aparecen las novelas de análisis psicológico de Marcel Proust y las impresionistas de Virginia Woolf, las narraciones de dimensiones míticas de James Joyce y las simbolistas de Kafka, que exploran nuevos dominios del individuo y la sociedad, así como nuevas técnicas de narrar, construir la trama y presentar los personajes.

En este sentido, algunas de sus narraciones ponen de manifiesto numerosas cuestiones sobre todos los aspectos de la realidad, llegando a expresarse con audacia y creando así un campo ampliado de posibilidades de expresión. Sin embargo, como afirma el propio Zafzāf, este logro no es suficiente; los narradores árabes, y especialmente los marroquíes, aún son víctimas de un fuerte sentimiento de abismo y soledad al verse obligados a recurrir con demasiada frecuencia a estrategias y ambages de autocensura ${ }^{16}$. En su caso, este sentimiento está generado por la particular situación política, social y cultural de que son testigos y que conduce a autores como Hānī al-Rāhib, Naŷîb Maḥūẓ o Suhayl Idrīs, Ḥalīm Barakāt o Laylà $\mathrm{Ba}^{\mathrm{c}}$ albakī a realizar en algunas de sus obras una comprensión del mundo a través del sentimiento de aislamiento, soledad y exilio ${ }^{17}$. En esta situación, el ser humano se halla sometido a una presión cruel por parte de la realidad; pero es el escritor, como ser más

${ }^{15}$ M. Zafzāf. Op. cit, p. 36.

${ }^{16}$ Véase a colación: M. Berrada. "Política cultural y libertad de expresión. La situación en Marruecos." Premier Encontre d'Escriptors del Mediterrani. Valencia, 1983, pp. 74-82. (Trad. C. Ruiz). P. Martínez Montávez. "Sobre el intelectual árabe y la lucha por la democracia" en, Literatura árabe de hoy. Madrid, 1990, pp. 179-196.

${ }^{17}$ M. Zafzāf. Op. cit. p. 36. 
sensible, el que mejor percibe y más sufre la contradicción y la dualidad.

En la novela tradicional, el objetivo último del escritor era hacer de sus héroes arquetipos vivos, bien definidos y con una posición concreta ante el mundo, con lo cual el escritor se caracterizaba a sí mismo y su verdad. En la narrativa árabe contemporánea hay numerosos casos de héroes arquetípicos (namāäiŷ) como el intelectual desvinculado de la realidad que siente el abismo existente entre él y el mundo. Otras veces el héroe trasciende su carácter de arquetipo y se convierte en "estado" (hâla), en virtud de lo cual el personaje ya no se conforma con la descripción externa, sino que ésta se disuelve para que pueda captarse mejor el estado interior por medio del cual se imponen obsesivamente sus ideas, dudas, rabias o desesperaciones, en busca de su posición en el mundo y de las aspiraciones humanas que lo sitúen en la dinámica de la naturaleza. El héroe deja de ser un personaje novelesco para convertirse, gracias a su situación actualizada, en actitud. La ficción pierde su dominio y el problema expuesto pasa a ser la cuestión fundamental, de modo que el autor aprovecha al máximo la situación del personaje en un intento de aproximar lo particular a lo general, y viceversa; de este modo, aquel abismo que separaba lo real de lo ficticio desaparece y el autor se acerca progresivamente al mundo haciendo sentir al lector que se halla inmerso en la sociedad, y no fuera. ${ }^{18}$ El elemento indispensable para intentar conseguir este objetivo es, junto con la puesta en práctica de las técnicas narrativas adecuadas, la audacia y la espontaneidad en el lenguaje. En la narrativa árabe no faltan ejemplos que demuestran la labor realizada en esta dirección por autores como los egipcios Yūsuf Idrīs (1927-1991), Sulayman Fayyāọ (n. 1929), Șunc Allāh Ibrāhīm (n.1937) o Yahyà al-Ṭāhir Ábd Allāh (1942-1981), entre otros, sin excluir al predecesor de todos ellos, Yahyà Haqqī (19051992), ${ }^{19}$ modelos de los que los narradores marroquíes de hoy toman buen ejemplo.

Por otra parte, podemos entrever en la concepción literaria de Muhammad Zafzāf la existencia de ciertos elementos presentes en otros narradores, occidentales y árabes, cuyas obras narrativas se apartan del modelo balzaquiano y se transforman en relatos abiertos, de perspectivas y límites inciertos, con personajes extraños y anormales, en los que los contornos de las cosas y los seres llegan a cobrar dimensiones irreales y significaciones alegóricas, y la trama es a veces confusa con el fin de expresar con autenticidad la vida y el destino humano, absurdo e incongruente. Además, la confusión de la cronología y la multiplicidad de planos temporales aparecen íntimamente relacionadas con el uso del monólogo interior y con la construcción de la narración sobre la memoria que recrea lo acontecido.

Sin embargo, tratándose de narrativa árabe contemporánea, y marroquí, como es el caso, no debemos olvidar las propias especificidades. Zafzāf se muestra consciente de ello y lo expresa. Si bien debemos reconocer que, salvo algunos casos muy relevantes a los que ya hemos hecho mención, aún son pocos los narradores marroquíes que demuestran poseer una

\footnotetext{
${ }^{18}$ M. Zafzāf. Op. cit. p. 37.

${ }^{19}$ Ibid.
} 
plena maestría lingüística y técnica, tampoco hay que olvidar que la narrativa árabe, no sólo en Marruecos, sino en todo el Magrib, está decisivamente condicionada por la situación socio-política y cultural particular de la zona y que afecta directamente a la producción literaria, tanto en su fase de creación y difusión como en su recepción por parte del lector. La narrativa marroquí actual cuenta con los esfuerzos de no pocos autores que en circunstancias sociales, políticas, morales y de publicación más favorables llegarían en poco tiempo a producir obras realmente interesantes. ${ }^{20}$

\section{Entre lo verdadero y lo verosímil.}

El espacio en el que tienen lugar las historias contadas en los relatos de Muhammad Zafzāf es siempre un ámbito en armonía con la caracterización y la actitud del personaje. El campo, y el espacio rural en general, es un ámbito de aislamiento y clausura en el que la fuerza de la naturaleza pone de manifiesto la impotencia e incapacidad del ser humano para incidir sobre su propio destino. El espacio natural abierto es a menudo el abismo al que el individuo se siente abocado y en cuyo filo se mantiene indeciso contemplando la situación propia y la de los demás. La ciudad es concebida en los relatos de Zafzāf como un ámbito de apertura, de expansión de los males de la sociedad moderna dominada por un interés materialista y un desarrollo urbano que acorrala y acaba por asfixiar los elementos tradicionales. La ciudad se presenta como lugar generador de opresión social e individual, que calificaríamos de "doméstica" por la inmediatez y cercanía con que es ejercida y sentida. No obstante, es también el único ámbito en el que existe una posibilidad remota de libertad. El espacio público, como la terraza de un café o la calle misma, se presenta en Zafzāf no como el punto de observación y denuncia que solía darse en el realismo crítico del intelectual autoexcluido de la sociedad, sino como el centro de exposición y exteriorización de actitudes y acciones que generalmente chocan con la opinión del entorno o son contrarias a la moralidad dominante. El tiempo en los relatos de Zafzāf suele mostrar dos aspectos: el tiempo real, inexorable, y el tiempo de la utopía, suspendido. A veces, ambas dimensiones temporales se enfrentan en la mente del personaje produciéndose así un escape de la realidad, en unos casos, o una desorientación inevitable causante de angustia existencial, en otros.

Los ámbitos descritos son recreados como microcosmos, no exentos de posibles interpretaciones simbólicas, en los que los personajes viven a merced de las circunstancias que les rodean. Los niños, casi siempre tempranamente maduros, son unas veces rebeldes que buscan un espacio de expansión y aventura, y otras veces víctimas indefensas de la injusticia social y la represión policial. En el otro extremo, los ancianos son individuos anónimos y marginados no sólo por la sociedad sino también por la familia, que han perdido las fuerzas para superar los obstáculos que les depara la vida y que asumen el hecho de que la muerte les acecha. Una amplia gama de mujeres aparecen recreadas en los relatos de

${ }^{20}$ M. Zafzāf. Op. cit. p. 38. 
Zafzāf: son esposas abnegadas, adúlteras, prostitutas, emigrantes, camareras, funcionarias, ladronas o extranjeras, pertenecientes al medio rural o al urbano, muchas de las cuales se diría han superado los condicionamientos morales y tabúes sexuales tradicionales profundamente arraigados en la sociedad musulmana contemporánea. Mujer y sexo son los dos ingredientes básicos de numerosos relatos de Zafzāf, en los que la situación que se produce sirve, no para evasión del protagonista como suele ocurrir en la narrativa de otros autores, sino para poner de manifiesto tres cuestiones controvertidas: la marginalidad de la mujer en la sociedad marroquí, la prostitución como medio de subsistencia y la necesidad de ruptura de tabúes; hechos que el narrador considera necesario, más que denunciar, expresar y airear sin paliativos argumentales y con un lenguaje directo en su afán por desvelar todo aquello que la moralidad social desea ocultar. También aparecen con frecuencia vagabundos y hombres desarraigados de cualquier origen, expulsados y perseguidos, que son víctimas de una especie de paranoia de la que el propio protagonista no es consciente.

Detectamos en la narrativa de Muhammad Zafzāf la proclamación tácita de una personal condición exílica. En sus relatos son frecuentes los espacios circulares de cuyo centro los personajes, ya sea por culpa del destino, de la miseria o de la ideología, tienden a ser víctimas de expulsión y arrojados al vacío. La desorientación y las barreras que obstaculizan la comunicación entre los individuos son a menudo la causa de un exilio interior de los personajes que llega a anular la solidaridad del yo con el otro. El tiempo contribuye a crear esta situación cuando fluye inexorable por cauces que se van estrechando progresivamente hasta alcanzar un vértice de inmovilidad y desilusión. La memoria, defectuosa unas veces, excesivamente imaginativa otras, suele ser en los retratos psicológicos de los personajes de Zafzāf propensa a evocaciones dolorosas y desprovista de esperanza en los esfuerzos de la voluntad humana contra el destino.

Si antes hemos explicado la concepción literaria de Muhammad Zafzāf parafraseando en lo fundamental sus propias palabras, consideramos oportuno concluir con algunas observaciones acerca de los posibles contactos entre sus relatos y la producción narrativa moderna tanto árabe como occidental. Arriba hemos apuntado diferentes consideraciones sobre las distintas influencias, orientales y occidentales, recibidas por la moderna narrativa marroquí y el modo en que éstas se presentan. En el caso de Muhammad Zafzāf observamos una actitud receptiva más reposada y selectiva en comparación con la que solíamos percibir entre los escritores marroquíes, y no sólo marroquíes, antes de los años setenta. La concepción del relato al modo de los autores árabes realistas de enfoque románticocostumbrista ha quedado atrás, de ellos este autor más que influencia recibe el fruto de sus aportaciones a la narrativa árabe moderna y la conciencia de estar ante un género literario que ofrece innumerables posibilidades. Más transparente es en los relatos de Zafzāf el conjunto de planteamientos temáticos y técnicos en consonancia con el relato realista orientado hacia la exploración de la esencia de la identidad nacional y sus aspiraciones. Y directa es la conexión con intelectuales y escritores progresistas testigos de una realidad socio-política fragmentada y creadores de literaturas "revolucionarias". Como rasgo muy personal, fruto de esta asimilación de lecturas, las necesidades primarias de la existencia 
humana aparecen en sus relatos como fotografías que antes del secado el autor sometiera a un proceso de manipulación a base de lirismo e introspección ${ }^{21}$. Los contactos con la narrativa occidental tienen lugar a través del recurso directo a las obras francesas y las traducciones a esta lengua de otras literaturas, como la rusa, la inglesa, la norteamericana e incluso la española e hispanoamericana. La lectura de la novela convencional, la subjetiva o la de los realistas rusos es insuficiente para la creación de una nueva literatura que refleje la identidad árabe, en general, y marroquí, en particular. De este modo, y como hacen sus coetáneos orientales, Zafzāf busca nuevos modelos más modernos y más en consonancia con la realidad árabe y marroquí de los años setenta y ochenta, que a veces encuentra entre las producciones de carácter simbolista, impresionista y existencialista, en las que este autor se inspira para expresar cuestiones humanas como las angustias, los tabúes y las utopías, con un lenguaje y audacia poco frecuentes en la narrativa marroquí. Observamos, pues, en Zafzāf una doble vocación, oriental y occidental, que en ningún caso actúa en detrimento del carácter específicamente marroquí de su producción narrativa, sino que por el contrario le confiere un personal rasgo de apertura de horizontes y, a la vez, de reconocimiento y aceptación de los múltiples factores que constituyen la realidad su país.

\section{La producción narrativa de Muhammad Zafzāf.}

Hasta el momento de redactar este trabajo, la producción narrativa de Muhammad Zafzāf consta de nueve colecciones de relatos, más un buen número de relatos aparecidos en revistas literarias árabes, incluidos la mayoría de ellos en las colecciones, y ocho novelas:

A) Colecciones de relatos:

1. Hiwār fĩ layl muta'ajjir (Diálogo al final de la noche). Damasco, Manšūrāt Wizārat alTaqāfa, 1970. 121 págs.

2. Buyūt wātị 'a (Casas bajas). Casablanca, Dār al-Našr al-Magribiyya, 1977 (1985 3ª ed.). 145 págs.

3. Al-Aqwà (El más fuerte). Damasco, Manšūrāt Ittihāâd al-Kuttāb al-ºArab, 1978. 101 págs.

4. Al-Šâyara al-muqaddasa (El árbol sagrado). Beirut, Dār al-Ādāb, 1980. 79 págs.

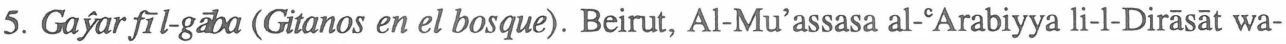
1-Našr, 1982. 111 págs.

6. Malik al-ŷinn (El Rey de los genios). Trípoli, Al-Manša'a al--Amma li-1-Našr wa-1-Tawzīi wa-l-I'lān, 1984. 101 págs. / Casablanca, Ifrīiyā al-Šarq, 1988. 99 págs.

7. Al-Malāk al-abyad (El ángel blanco). El Cairo, Al-Hay'a al-Miṣriyya al-'Amma li-1Kitāb. 1988. (Mujtārāt Fuṣūl Šahriyya, 51). 123 págs.

8. $A$ - $^{c}$ Araba (El coche). Rabat, Manšūrāt ${ }^{\circ} U k a ̄ z$, 1993. 102 págs.

\footnotetext{
${ }^{21}$ Posibles resonancias del sirio Zakaryā' Tāmir. Idea apuntada por P. Martínez Montávez. Introducción... p. 231.
} 
9. Bā'i icat al-ward (La Florista). Rabat, Manšurāt 'Ukāz, 1996. 128 págs.

B) Relatos aparecidos en revistas:

1. "Awdat Abā Hašūm" ("El regreso de Abā Hašūm"). Âfāq 2 (1965).

2. "Arabat al-aṭ̂āl al-ṣagīra" ("El cochecito de niño"). Aqlām 2, 3 (1966) 43-50.

3. "Fī intizāar al-nawm" ("Esperando al sueño"). Al-Ādāb V (1967) 25-30.

4. "Al-Mawt wa-mā bacda-hu" ("La muerte y lo que hay después"). Al-Ādāb VII (1968) 4850.

5. "Al-Tiifl wa-1-kalb" ("El niño y el perro"). Al- ${ }^{c}$ Alam al-Taqā̃̂̄î(14-3-1969).

6. "Anšūdat al-masā' al-ḥazīna" ("Himno triste del atardecer"). Āfāq 4 (1969).

7. "Al-Ḥiṣān al-bašarī" ("El centauro"). Āfāq 4 (1969).

8. "Takwīn aw šay' ismu-hu al-taḍajjum fĩ 1-'alāqa" ("Constitución o Algo llamado profundizar en las relaciones"). Al-'Alam al-Taqājī (21-8-1969).

9. "Al-Dafn" ("El entierro"). Al-Maŷalla (Agosto, 1969).

10. "Hal tadbulu al-azhār?" ("¿Se marchitan las flores?). Al- ${ }^{c}$ Alam al-Taqāầi (21-11-1969).

11. "Tafsīr wa-i'lān 'an al-hudūd al-muhịta bi-nā" ("Explicación y proclama de los límites que nos rodean"). Al- ${ }^{c}$ Alam al-Taqấfí (26-12-1969).

12. "Al-Dīdān al-latī tanḥan̄̄" ("Los gusanos que se inclinan"). Al-Maŷalla 8 (1970).

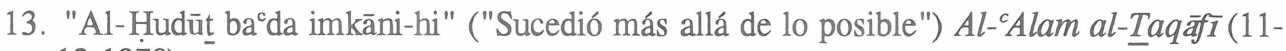
12-1970).

14. "Rasā'il aṣwāt aŷniḥa" ("Cartas, voces y alas"). Al-'Alam al-Ṭaqāî̀ (6-4-1971).

15. "Lucbat amāma al-Bund Strīt" ("Jugada frente a Bond Street") Al-Alam al-Taqāẫ̄ (4-61971).

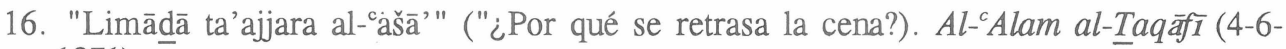
1971).

17. "Al-Dubāba wa-l-tawr" ("La mosca y el buey"). Al-'Alam al-Taqājî̀ (11-6-1971).

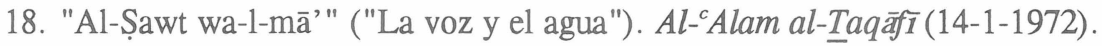

19. "Al-Kalīm al-mawșūf" ("Un interlocutor particular"). Al-c'Alam al-Taqāẫi (7-7-1972).

20. "Fī makān mačzūl" ("En un lugar apartado"). Al-Ādāb V (1973) 16-19.

21. "Muškilat kull yawm" ("El problema de cada día"). Al-Ādāb VII (1974) 46-49.

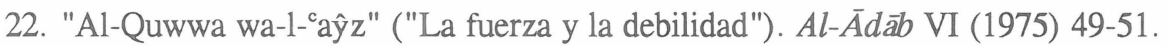

23. "Mawsim ziyārat al-sayyid" ("Época de visita al señor"). Al-Muharrir (24-8-1975) 4.

24. "Awhām" ("Fantasías"). Al-Ādāb III (1978) 35-38. 
25. "Al-Aqwà" ("El más fuerte"). Âfāq 3 (al-silsila al-ŷadīda) (1979?), 68-71.

26. "Al-Ḥadiqqa" ("El parque"). Al-Fuṣūl al-Arbac 4, 13 (marzo, 1981) 206-212.

27. "Fī l-gāba" ("En el bosque"). Al-Karmal 2 (1981) 52-63.

28. "Anțūnyū" ("Antonio"). Al-Karmal 5 (1982) 251-256.

29. "Al-Yafāf" ("La sequía"). Āfāq 10 (al-silsila al-ŷadīda) (1982) 124-127.

30. "Al-Gaylam" ("La tortuga"). Al-Karmal 10 (1983) 137-147.

31. "Hikāyat raŷul šārib" ("Historia de un bebedor"). Ibdæ̋ 6 (1984) 59-61.

32. "Al-Dalill" ("La prueba"). AL-Ma crifa 24, 280 (1985) 134-141.

33. "Al-Irt" ("La herencia"). Al-Wahda 2, 13 (1985) 134-136.

34. "Arabat al-nisā’" ("El vagón de las mujeres"). Al-Wahda 4, 41 (1988) 122-124.

C) Novelas:

1. Al-Mar'a wa-l-warda (La mujer y la rosa). Beirut, Al-Dār al-Muttahida li-1-Našr, 1970 y 1972 (2a ed.). Rabat, Al-Sarika al-Magribiyya li-l-Nāširīn al-Muttahidīn, 1987. 110 págs.

2. Arșifa wa-ŷidrān (Aceras y muros). Bagdad, Manšūrāt Wizārat al-I'lām al-I'rāqiyya, 1974. (Silsilat al-Kitābāt al-Yadìda, 1). 155 págs.

3. Qubūr fị l-mā' (Tumbas bajo el agua). Túnez, Al-Dār al-Tūnisiyya li-l-Našr, 1978.

4. Al-Af ${ }^{c} \dot{a}$ wa-l-bahr (La serpiente y el mar). Casablanca, Al-Matābi ${ }^{\mathrm{c}}$ al-Sarīa a, 1979. 100 págs.

5. Baydat al-dik (El huevo del gallo). Casablanca, Manšūrāt al-Ŷāmica, 1984.

6. Muhāwalat ${ }^{c}$ ayš (Intentando sobrevivir). Túnez, Al-Dār al-Tūnisiyya li-1-Našr, 1985. 144 págs.

7. Al-Taclab al-lad̄̄ yazhar wa-yajtafī (El zorro que viene y va). Casablanca, Manšūrāt Aw⿳rāq, 1989.

8. Al-Hayy al-jalfĩ (El barrio de atrás). Rabat, Manšūrāt ${ }^{\circ} \bar{A} l a m$ al-Șahạâa, 1992. 90 págs.

D) Traducciones al español:

1. "El niño y el perro" Marruecos, 21-3-1977. (Trad. Fernando de Ágreda)

2."Tumbas bajo el agua" (fragmentos), en Literatura y pensamiento marroquíes contemporáneos. Madrid, I.H.A.C. y Facultad de Letras de Rabat, 1981. (Serie "Antologías Nacionales" III) Págs. 294-309. (Trad. M. El Geady).

3. "El saltamontes", en Del Atlas al Tigris. Relatos árabes de hoy. Madrid, CantArabia, 1985. pp. 109-112. (Trad. C. Ruiz). 
4. "Cartas, voces y alas", en Antología de relatos marroquíes. Murcia, Universidad de Murcia, 1990. pp. 137-144. (Trad. A. Limami).

5. "La mujer y la rosa. (En Torremolinos)", en Miradas desde la otra orilla. Una visión de España. Madrid, I.C.M.A., 1992. pp. 123-127. (Trad. fragmentos A. Djibilou).

6. Dos relatos: El huevo del gallo. El zorro que viene y va. Madrid, CantArabia, 1992. (Trad. R. Montoro y C. Ruiz).

7. La mujer y la rosa. Madrid, Agencia Española de Cooperación Internacional, 1997. Col. «Autores Árabes Contemporáneos» nº 20. (Trad. del árabe y presentación por Beatriz Molina Rueda y Zouhir Louassini).

8. El Rey de los genios y otros relatos. Madrid, Huerga \& Fierro, (en prensa). (Selección de relatos, traducción del árabe y presentación por Fernando Ramos). 